\title{
Undergraduate veterinary education
}

K.P. Pettey

ken.pettey@up.ac.za

Department of Production Animal Studies, Faculty of Veterinary Science, University of Pretoria, Onderstepoort 0110, South Africa

This paper is part of the special issue entitled: 8th International Sheep Veterinary Congress, Guest Edited by D.M West and A. Ridler.

\section{Abstract}

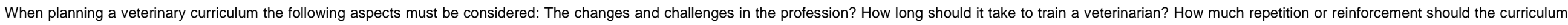

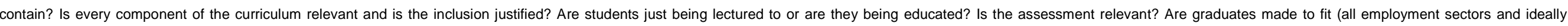

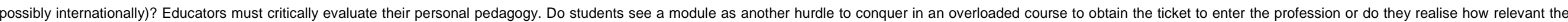
module is?

Keywords: Veterinary curriculum planning; Knowledge retention; Peer instruction; Peer assessment; Group assessment

\section{Introduction}

The veterinary profession is very diverse. Graduates are employed by the state and private sectors. In both sectors there are opportunities to work with companion animals, production animals and wildlife. There are many facets to successfully educating veterinarians:

1. The selection of students should include the following criteria:

- knowledge of the profession in all its facets

- passion to become a veterinarian

- integrity towards the profession and clients

- intellectual quotient (IQ)

- emotional quotient (EQ)

2. Needs of the profession:

- predictions of how veterinary science will develop in the next $10-20$ years - what the

country and its communities require with regards to veterinary services

3. A well planned curriculum must:

- be outcomes based

- ensure limited or appropriate repetition between subjects -

include subjects dealing with professional life and health -

encourage self-driven (guided) learning 
- a computer laboratory is a key requirement

- skills laboratories will streamline skills acquisition

- assessment must be appropriate

\section{Discussion}

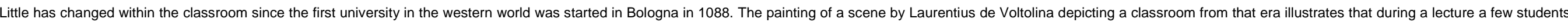

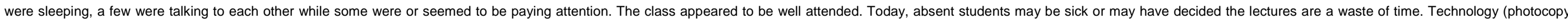
machines, audio visual recording machines and computers) aids absenteeism. Some students may elect to surf the world wide web or search the library for information on the lecture topic that may be relevant.

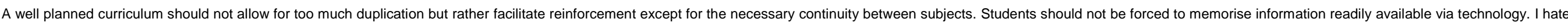
hearing: "I had to suffer doing this as a student so my students must also suffer....". If the information is really important, it will automatically be remembered because of regular use.

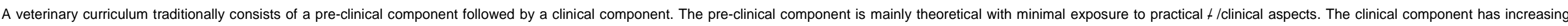
practical $+/$ clinical aspects with greatly reduced theoretical input - with the final year being almost solely clinical.

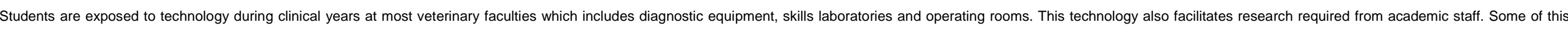
equipment may have been purchased via research grants. Research is an income generating avenue for universities.

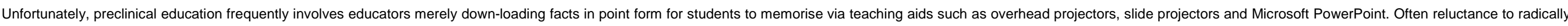
modify the preclinical training is because:

\section{- these methods worked for decades i.e.: pedagogy lecturers received}

- students are accustomed to being spoon-fed, facilitating easy recall from short-term memory and resultant good grades

- funding to upgrade/modify lecture facilities is a problem

- funding/remuneration formulae at tertiary institutions is pushing educators to become researchers, resulting in less time spent planning and preparing for educating

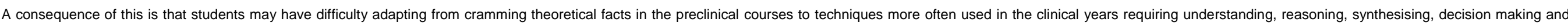
implementation.

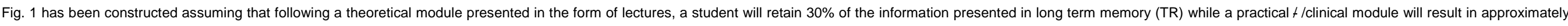
$70 \%$ of the information being retained in long term memory (PR). The summation of the information retained in long term memory for theoretical and practical $t / c$ linical components for each year results in the line (Sum). This 

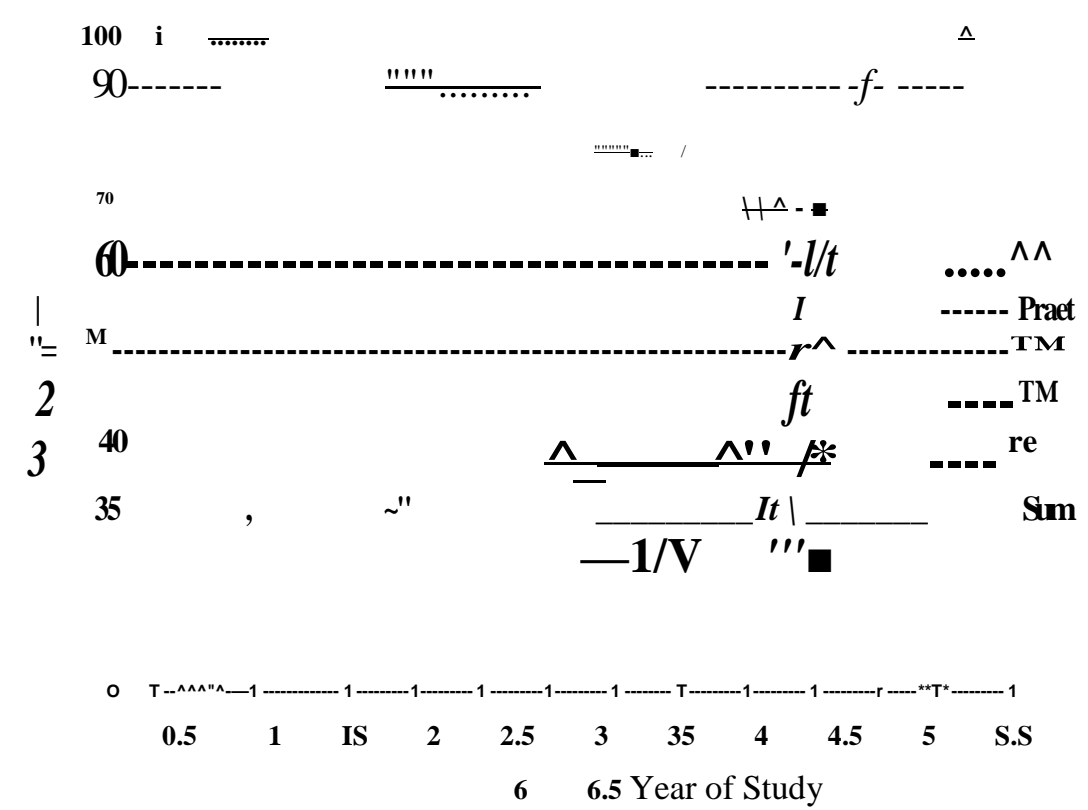

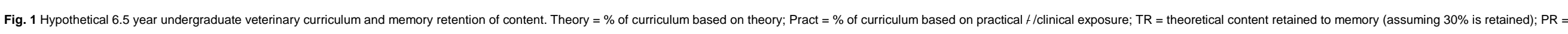
practical $+/$ clinical content retained to memory (assuming $70 \%$ is retained); Sum = summation of retention to memory of the theoretical and practical content.

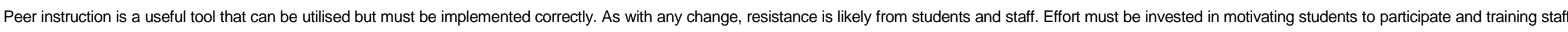

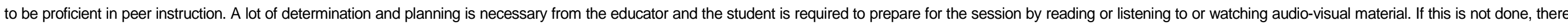

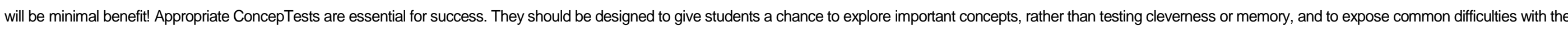

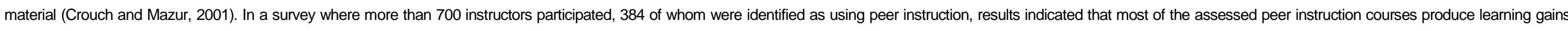

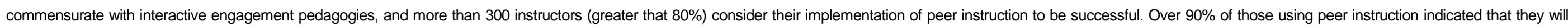
continue or will expand their use of peer instruction (Fagan et al., 2002).

An added advantage of peer instruction is that it has been shown to reduce student attrition in science programmes (Lasry et al., 2008).

Once implemented, student reaction is generally positive (Crouch and Mazur, 2001).

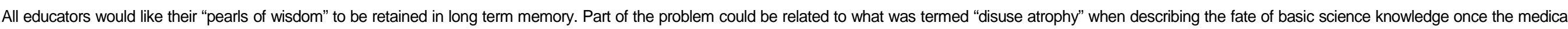

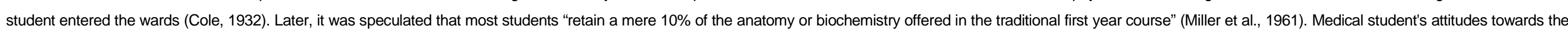

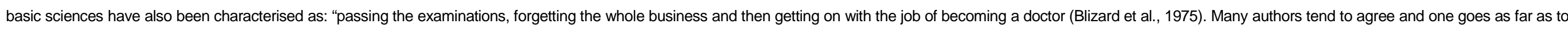

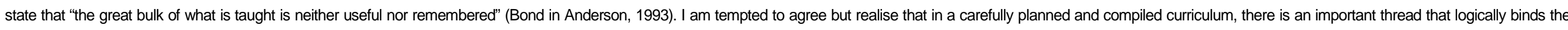

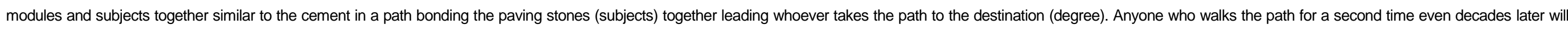

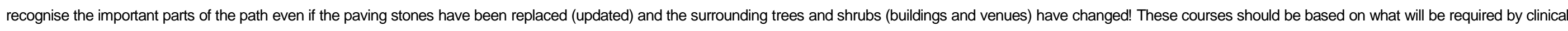
subjects later on in the curriculum and ultimately after graduating (outcomes based) and not contain superfluous content!

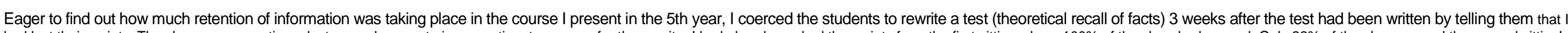

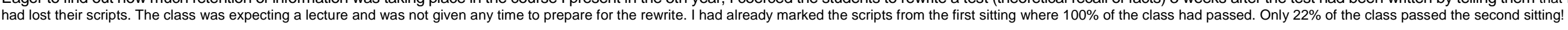




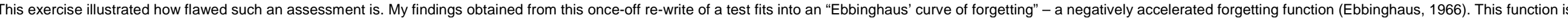

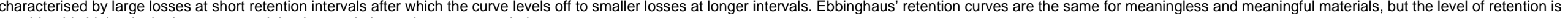

considerably higher in the latter case and the time scale is much more expanded.

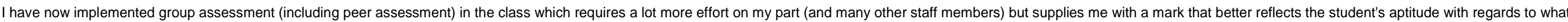

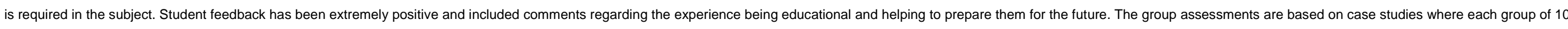

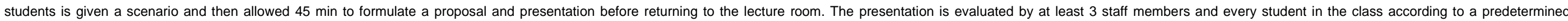

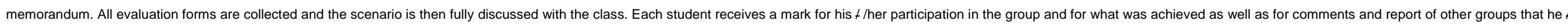
Ishe assessed.

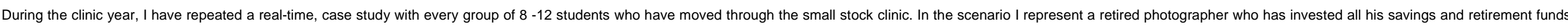

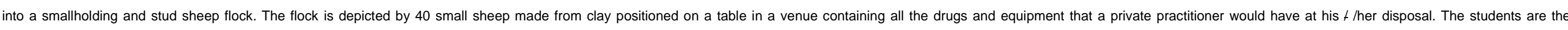

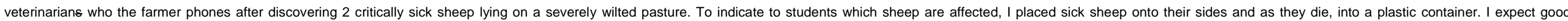

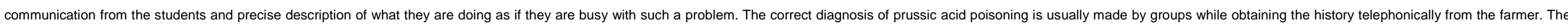

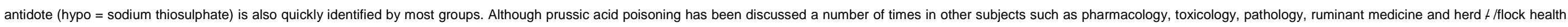
the majority of groups still don' not suggest or do the following:

- request the farmer to get plenty of hot water ready (to dissolve hypo - endothermic reaction) before arriving at the farm. I require students to mix the hypo in the correct proportion with water.

- carry out a quick necropsy to confirm the diagnosis on arrival at the farm (check colour of the blood - cut jugular vein and puncture rumen to detect almond aroma)

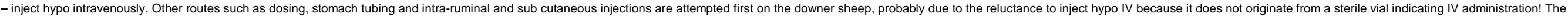
reaction to treatment will confirm the diagnosis and lead the students on to dealing with possible relapses and future prevention

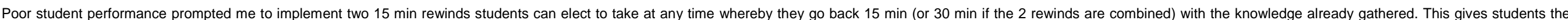
opportunity to observe what impact each step has regarding the survival of patients.

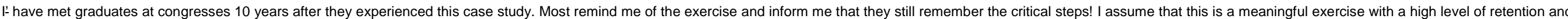
a much expanded time scale.

\section{Conclusion}

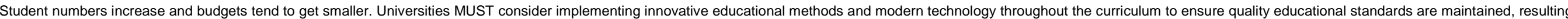
in capable graduates, employable internationally.

An educator with passion and vision will remain relevant

Lecturers may become redundant ... educators will always be needed

\section{Conflict of interest statement}

I wish to confirm that there are no known conflicts of interest associated with this publication and there has been no significant financial support for this work that could have influenced its outcome.

confirm that I have studied the manuscript and there are no other persons who satisfy the criteria for authorship.

I confirm that I have given due consideration to the protection of intellectual property associated with this work and that there are no impediments to publication, including the timing of publication, with respect to intellectual property. 


\section{Uncited references}

Custers (2010) and Kerfoot et al. (2007)

\section{Acknowledgment}

Thanks to Professor Gareth Bath for sharing his philosophy of education with me and for assisting me with the implementation of my ideas.

\section{References}

Anderson J., The continuum of medical education: the role of basic medical sciences, J R. Coll. Physicians Lond. 27, 1993, 405-407.

Cole L., What is wrong with the medical curriculum?, Lancet 110, 1932, 253-254.

Crouch C.H. and Mazur E., Peer instruction: ten years of experience and results, Am. J. Phys. 69 (9), 2001, 970-977.

Custers E.J.F.M., Long-term retention of basic science knowledge: a review study, Adv. Health Sci. Educ. 15, 2010, 109-128.

Ebbinghaus, H., 1966. http://psychclassics.yorku.ca/Ebbinghaus/index.htm

Fagan A.P., Crouch C.H. and Mazur E., Peer instruction: results from a range of classrooms, Phys. Teach. 40, 2002, 206-209.

Kerfoot B.P., DeWolf W.C., Masser B.A., Church P.A. and Federman D.D., Spaced education improves the retention of clinical knowledge by medical students: a randomised controlled trial, Med Educ. 41, 2007, 23-31.

Lasry N., Mazur E. and Watkins J., Peer instruction: from Harvard to the two-year college, Am. J. Phys. 76 (11), 2008, 1066-1069.

Miller G.E., Graser H.P., Abrahamson S., Harnack R.S., Cohen I.S. and Land A., Teaching and learning in medical school, 1961, Harvard University Press; Cambridge MA. 